\title{
The Influence of Compensation Management Strategy on Talent Retention: Exploring the Mediating Role of Structural Capital
}

\author{
Azzam A. Abou-Moghli ${ }^{1}$ \\ ${ }^{1}$ Department of Business Administration, Faculty of Business, Applied Science Private University, Amman, \\ Jordan \\ Correspondence: Azzam A. Abou-Moghli, Department of Business Administration, Faculty of Business, Applied \\ Science Private University, Amman, Jordan.
}

Received: February 5, 2019

Accepted: February 19, 2019

Online Published: February 28, 2019

doi:10.5539/ibr.v12n3p165

URL: https://doi.org/10.5539/ibr.v12n3p165

\begin{abstract}
Background: Retention of the employees is recognized as one of the significant problems of the present business world. The retention phenomena are observed to be impacted by the compensation practices employed by the firm.

Objective: Based on this, the study aims to assess the compensation management strategies among Jordan commercial banks using structural capital approach.

Methods: The study employed a quantitative design for assessing the employee retention. For this, data collection has been done using a survey based on a questionnaire.

Results: The study has found a significant and positive impact of work life balance, satisfaction, and benefits on structural capital and talent retention. Moreover, the study failed to report a significant impact of salary on opportunity and job nature.

Conclusion: The structure of the compensation management in the banking sector must encourage a new design for improving its impact intensity.
\end{abstract}

Keywords: compensation management strategy, talent retention, structural capital, Jordan

\section{Introduction}

In the present globalized economy, the significance of growth, advancement and sustaining a work-life balance cannot be ignored (Lim et al., 2015). The need for these factors serves as a stimulus leading the employee to switch from one firm to another. This is evident from the reported turnover of $9.6 \%$ in 2016 (Lowers \& Associates, 2018). Weigold et al. (2013) propose that the main reason why employees switch firms is the believe that they cannot achieve their ambitions; therefore, they search for the right workplace that would allow such possibility. This is based on their evaluation for the determined career objectives within their control that may not be aligned to objectives of the firm that are central to the formation of a dependable base for profit. In this regard, the study by Loan-Clarke (2010) asserts that misalignment of the employee wants and firm objectives can lead to increased employee turnover.

Even though the general context of the employee turnover cannot be completely understood, several studies have been conducted for clarifying the factors which increase its prospects. The research by Ashar (2013) asserts that the turnover of the employee stems from his need for career development, while also highlighting it as a contributing factor to his retention. Various strategies have been implemented by the firms for enhancing their commitment such as the offering of better wages, training, compensation packages, and knowledge and development opportunities for ensuring employee satisfaction. (Walia \& Bajaj, 2012). Rahim et al. (2011) argues that the satisfaction of the employee is linked to his compensation package. For employees, the nature of the compensation packages serves as a source for meeting their wants and needs. Since it entails the fundamental elements of employee satisfaction such as salaries, bonuses and incentives, its significant impact has been reported by several studies (Ahmed et al., 2011).

Various researchers such as (Bartlett \& Ghosal, 2013) have indicated the relationship between compensation strategies and employee retention. Additionally, the study by Mokaya and Kipyegon (2014) has stressed upon the 
firms to form a connection between employee personal effort and remuneration in order to improve its workforce productivity. The substantial increase in the stakeholder demand for transparency of the business practices has driven firms to adopting a new system for quantifying and reporting. This necessitates the incorporation of structural capital (Gogan et al., 2015). Moreover, innovative strategies towards compensation have also reported having a substantial impact on the firms' practices (Adeoye \& Fields, 2014). Reflecting upon the economy inclination towards knowledge, the development of the structural capital serves as a catalyst for increasing employee's retention. The study by Guan et al. (2015) has emphasized the integration of the key learning aspects into its retention strategy for sustaining its top talent and sustaining its competitive edge in the competitive business environment. For maintaining the firm talented workforce, the integration of the intellectual capital using structural capital has been reported (Aramburu \& Sáenz, 2011). The concept of structural capital is inclusive of the firms' processes, practices, technologies, and information resource as well as intellectual property rights (Mertins et al., 2009). Given this, Aramburu, and Sáenz, (2011) highlights the significance of structural capital by reporting it as an agent which retains the structures, manuals, and training materials even when the employee is no longer associated with the firm. In other words, structural capital assimilates in knowledge and intangible assets, which stems from the firm processes and incorporates efficiency, procedural innovativeness, and information accessibility. The use of these structures allow the employees to enhance their productive capacity. In addition to this, the study of Rahim et al. (2011) can be considered which has elucidated the effectiveness of the structural compensation strategy for improving business performance and strengthening the employee retention within the Malaysian firms. Given the dynamics of the innovative world, it is integral to have the capacity to imitate the dynamic capabilities, which can continually yield, expand, enhance and safeguard the firms' unique asset base.

The needs are further amplified in the context of the banking sector. The turnover of employees in the banking sector significantly thwarts its profitability prospects. With regard to the dynamic nature of the bank, the unstructured retention of the employees can substantially increase its volatility aspects (Yin-Fah et al., 2010). This makes it important for the leadership of banking sector to comprehensively understand the need to tie its profitability and growth prospects to not only employee remuneration but also to his career development (Gratton \& Erickson, 2007). Samuel and Chipunza (2009) has argued that firms must offer their employee some rewards (intrinsic/extrinsic) along with career progression opportunities to ensure their loyalty, satisfaction, and increasing their retention prospects.

The movement of skilled workforce between different banks in Jordan has been reported in this sector, which affects negatively its effectiveness and performance. Therefore, the study attempts to assess the effect of compensation management on employee retention using structural capital as a mediating factor. The significance of this study lies in the fact that it highlights the unique significance of compensation with regard to employee retention in the Jordan commercial banking industries. Moreover, the retention aspect of an employee using the structural capital approach as a mediator has not been studied previously (Shahnawaz \& Jafri, 2009). The study helps in evaluating the best retaining abilities of these bankers for overcoming constant mobility. Additionally, the results of the study are assumed to be valuable in devising decisions for improving employee's retention in Jordan banks.

\section{Conceptual Framework and Hypothesis Development}

It is very crucial for firms to face the challenges of employee retentions due to increasing competition in industry. Many firms face challenges in hiring skilled employees. Management and top-level executives spend their time, effort and money to retain key employees in a firm. In this context, Haider et al., (2015) examine practices of human resources management regarding employee retention in telecom sector. He reveals that compensation strategy and culture of a firm positively affect the relationship of employee retention in firms. According to Mabaso and Dlamini (2017) state, that compensation strategy of firms plays an energetic role in appealing, encouraging and retaining talented employees of the firm. It reassures effective employees to remain in contract the firm for long-term and serve the firm with their talented skills. Remuneration in the main foundation of this employee-employer relationship. It has a strong impact on employee's job satisfaction. In the light of Michael et al. (2016) study, he analyzed a substantial relationship among employee retention, his appreciation towards job, and satisfaction in environment and culture of a firm. He sustains that the more employee is rewarded by a firm, the longer he remains in a firm, being beneficial for the firm. It is further supported by Obeidat (2016) study that structural capital is an important factor in achieving goals for the firm to be successful. It deals with the structure of a firm, which deals with the innovations and mechanisms, being an important part of the firm resources. Thus, the firm who preserves a strong capital will implement a supportive culture where employees can try, learn and practice innovative things despite of loss or profits (Ismail, 2005). 
Such practices of human resource management highly influence the performance of firm by affecting structural capital of a firm which are conceptualize as the valuable resources of the firm (Bode et al., 2015). On the other hand, many researchers assume structural capital as idol assets of the firm, which includes database, files, trademark and structures. Because when employees leave the firm, these assets remain with the firm. This is certainly true that structural capital and compensational strategies plays an important role in firm performances. Specialists of human resource management are always anticipated to reconsider companies' strategies and reward programs to guarantee and address employees' motivation and commitment towards the success of the firm. If satisfying job opportunities are offered, it is believed to in augmentation of employee retention. Many other strategies proposed by Mabaso and Dlamini (2017) includes employee rewards, cash incentives, medical and educational allowances, performance bonuses, employee benefit funds, new hiring and referral offers aids in reducing employee retention and makes it difficult for an employee to leave a firm. Based on the above literature review discussion the following conceptual framework and hypotheses are developed.

Hla: there is positive and significant influence of work life balance on opportunities.

H2a: there is positive and significant influence of salary on opportunities.

H3a: there is positive and significant influence of satisfaction on opportunities.

H4a: there is positive and significant influence of benefits on opportunities.

H5a: there is positive and significant mediation influence of structural capital on opportunities.

H6a: there is positive and significant mediation influence of structural capital on job nature.

H7a: there is positive and significant influence of work life balance on job nature.

H8a: there is positive and significant influence of satisfaction on job nature.

H9a: there is positive and significant influence of salary on job nature.

H1Oa: there is positive and significant influence of benefits on job nature.

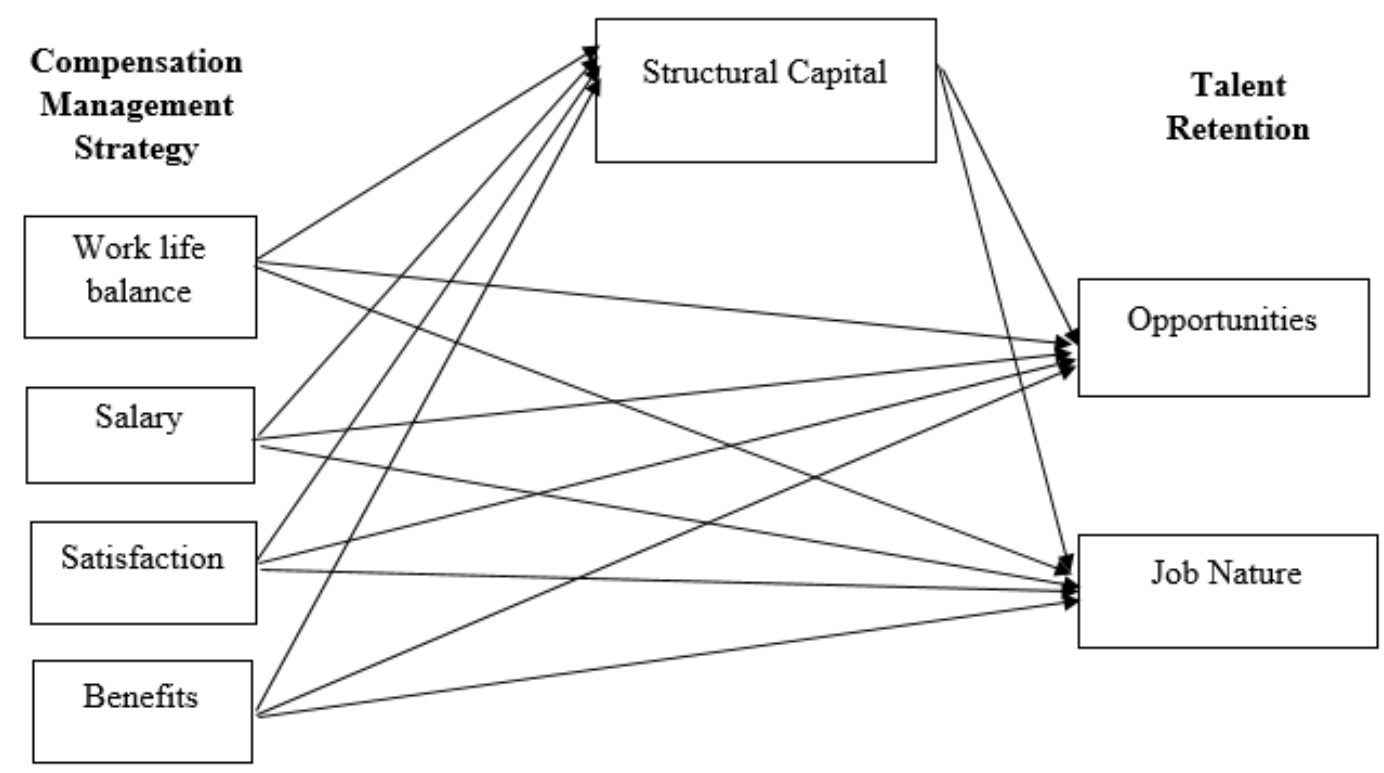

Figure 1. Conceptual Framework

\section{Methodology}

\subsection{Study Design}

In the present study, the quantitative research design is employed. The selection of the particular design is based on its effectiveness for collecting and evaluating data (Polit \& Beck, 2016). Moreover, its representation in the form of statistics makes its comprehension easy for the reader.

\subsection{Study Population and Sample}

Since there are 13 commercial banks in Jordan, all of the banks were targeted; therefore, there was no need for 
sampling. The population determined for the study constitute of managers and supervisors employed at the top and middle management of banks in Jordan, because they are considered the most experienced respondents concerning the variables used in the study. A total of 367 questionnaires were distributed. Only 322 questionnaires were returned properly filled, yielding a response rate of $87 \%$.

\subsection{Data Collection}

The study conducted a survey for collecting the data from the bankers. For this, it used a close-ended questionnaire. The instrument of the questionnaire was used as it allows gathering the data in an easy and speedy manner. The items on the questionnaire were categorized into four parts. The first part encompasses items which collect the demographic details of the managers and supervisors. While the second part focuses on compensation management which is further categorized into four subparts such as work-life balance, salary, satisfaction, and benefits. Whereas, the third part deals with structural capital which comprises of firm structure and social structure as its subcomponents. The last part in the questionnaire is focused on talent management which is further categorized into three parts such as development opportunities, and job nature. Each part in the questionnaire comprises of three items, which sums up to 24 items in the questionnaire. Moreover, a 3-point Likert scale is used where each item can be marked from 1 likely to 3 unlikely. The utilization of this scale makes it easy for the participant to respond to the particular item, as per their view.

\subsection{Data Analysis}

The study used IBM SPSS version 22.0 for analyzing the gathered data. path analysis and confirmatory factor analysis has been performed using structural equation modeling.

\section{Results}

Prior to the distribution of the questionnaire, the reliability of the items was assessed using the questionnaire. Table 1 exhibits the achieved value of the questionnaire items.

Table 1. Questionnaire Reliability

\begin{tabular}{|c|c|c|}
\hline \multicolumn{2}{|c|}{ Variables } & Number of Items \\
\hline \multicolumn{3}{|c|}{ Compensation Management } \\
\hline \multicolumn{3}{|c|}{ Work-Life Balance } \\
\hline & CMW1 & 0.776 \\
\hline & CMW2 & \\
\hline & CMW3 & \\
\hline \multicolumn{3}{|l|}{ Salary } \\
\hline & CMS1 & 0.784 \\
\hline & CMS2 & \\
\hline & CMS3 & \\
\hline \multicolumn{3}{|l|}{ Satisfaction } \\
\hline & CMSF1 & 0.742 \\
\hline & CMSF2 & \\
\hline & CMSF3 & \\
\hline \multicolumn{3}{|l|}{ Benefits } \\
\hline & CMB1 & 0.875 \\
\hline & CMB2 & \\
\hline & CMB3 & \\
\hline \multicolumn{3}{|l|}{ Structural Capital } \\
\hline \multicolumn{3}{|l|}{ Firm Structure } \\
\hline & OS1 & 0.894 \\
\hline & OS2 & \\
\hline & OS3 & \\
\hline \multirow[t]{4}{*}{ Social Structure } & & 0.875 \\
\hline & SS1 & \\
\hline & $\mathrm{SS} 2$ & \\
\hline & SS3 & \\
\hline \multicolumn{3}{|c|}{ Talent Management } \\
\hline \multicolumn{3}{|c|}{ Development Opportunities } \\
\hline & DO1 & 0.789 \\
\hline & DO2 & \\
\hline & DO3 & \\
\hline \multicolumn{3}{|l|}{ Job Nature } \\
\hline & JN1 & 0.987 \\
\hline & $\mathrm{JN} 2$ & \\
\hline & JN3 & \\
\hline
\end{tabular}


Table 2 indicated factor loadings based on exploratory factor analysis, in which all values should be greater than 0.60 and the whole variance should to be greater than 60 percent. In the table below, all items have achieved higher values than the cutoff point of 0.60 for loading. The whole variance of the model was also 85 percent, indicating that exploratory factor analysis results were exact and satisfactory according to the recommended cutoff point.

Table 2. Rotated Component Matrix

\begin{tabular}{|c|c|c|c|c|c|c|c|}
\hline & & & & Cor & onent & & \\
\hline & 1 & 2 & 3 & 4 & 5 & 6 & 7 \\
\hline WB3 & .898 & & & & & & \\
\hline WB2 & .889 & & & & & & \\
\hline WB1 & .799 & & & & & & \\
\hline SAL1 & & .898 & & & & & \\
\hline SAL2 & & .854 & & & & & \\
\hline SAL3 & & .862 & & & & & \\
\hline SAT2 & & & .875 & & & & \\
\hline SAT3 & & & .763 & & & & \\
\hline SAT1 & & & .754 & & & & \\
\hline BEN2 & & & & .952 & & & \\
\hline BEN3 & & & & .946 & & & \\
\hline SC2 & & & & & .786 & & \\
\hline SC1 & & & & & .746 & & \\
\hline SC3 & & & & & .689 & & \\
\hline OPP1 & & & & & & 0.925 & \\
\hline OPP3 & & & & & & 0.775 & \\
\hline OPP2 & & & & & & 0.859 & \\
\hline JN1 & & & & & & & 0.839 \\
\hline JN3 & & & & & & & 0.978 \\
\hline JN2 & & & & & & & 0.856 \\
\hline Total & 2.375 & 2.254 & 1.998 & 1.621 & 1.687 & 1.781 & 1.787 \\
\hline$\%$ of Variance & 15.752 & 15.312 & 14.369 & 15.016 & 12.052 & 13.001 & 13.156 \\
\hline Cumulative \% & 15.751 & 34.064 & 48.323 & 59.349 & 73.391 & 82.258 & 85.486 \\
\hline
\end{tabular}

Table 3 below shows the construct validity through the factor loading test for all the items. The cutoff point of factor loading has been set at 0.60 . Accordingly, the model below shows greater values than the set cutoff point (0.60). The study achieved validity of construct to all items excluding item SCP3, which demonstrates a value of 0.510 (lower than the set cut off point). Nonetheless, the overall value of the model is acceptable and therefore the model considered valid for analyses.

Table 3. Construct Validity

\begin{tabular}{|c|c|c|c|c|}
\hline & & & Estimate & P Value \\
\hline WB3 & $\begin{array}{ll}<-- \\
\end{array}$ & Work life balance & 0.898 & 0.000 \\
\hline WB2 & $<---$ & Work life balance & 0.924 & 0.000 \\
\hline WB1 & $<---$ & Work life balance & 0.578 & 0.000 \\
\hline SAL1 & $<---$ & Salary & 0.863 & 0.000 \\
\hline SAL2 & $<---$ & Salary & 0.889 & 0.000 \\
\hline SAL3 & $<---$ & Salary & 0.737 & 0.000 \\
\hline SAT2 & $<--$ & Satisfaction & 0.889 & 0.000 \\
\hline SAT3 & $<---$ & Satisfaction & 0.568 & 0.000 \\
\hline SAT1 & $<---$ & Satisfaction & 0.679 & 0.000 \\
\hline BEN2 & $<---$ & Benefits & 0.895 & 0.000 \\
\hline BEN3 & $<--$ & Benefits & 0.773 & 0.000 \\
\hline $\mathrm{SC} 2$ & $<---$ & Benefits & 0.658 & 0.000 \\
\hline SC1 & $<---$ & Structural capital & 0.582 & 0.000 \\
\hline SC3 & $<---$ & Structural capital & 0.510 & 0.000 \\
\hline OPP1 & $<---$ & Opportunity & 0.789 & 0.000 \\
\hline OPP3 & $<---$ & Opportunity & 0.796 & 0.000 \\
\hline OPP2 & $<---$ & Opportunity & 0.872 & 0.000 \\
\hline JN1 & $<---$ & Job nature & 0.809 & 0.000 \\
\hline JN3 & $<---$ & Job nature & 0.852 & 0.000 \\
\hline JN2 & $<---$ & Job nature & 0.495 & 0.000 \\
\hline
\end{tabular}

The table below displays that there must be fulfillment of all the fit indices in both models. Hair et al. (2010) endorsed all the fit indices except for item AGFI > 0.85, which was proposed by Cole (1987). Consequently, and based on the results, CFA and SEM model values have been validated and substantially accurate in nature (Table 4). 
Table 4. Model Fit Indices

\begin{tabular}{lccc}
\hline & Threshold & CFA & SEM \\
\hline CMIN/DF & $<3.00$ & 2.869 & 1.971 \\
GFI & $>0.80$ & 0.982 & 0.922 \\
AGFI & $>0.80$ & 0.896 & 0.974 \\
CFI & $>0.90$ & 0.944 & 0.944 \\
TLI & $>0.80$ & 0.981 & 0.931 \\
NFI & $>0.80$ & 0.865 & 0.886 \\
RMSEA & $<0.08$ & 0.061 & 0.062 \\
PCLOSE & $>0.10$ & 0.179 & 0.155 \\
\hline
\end{tabular}

Table 5 below presents the results of discriminant validity test; the discriminate validity is the measurement of the interrelation between the items of the variables. Since the constructs of the items were established through theoretical grounds, the test below measures the variance among items to confirm their separate functionality and individuality. According to Hair et al. (2010) all construct variables based on AVE square root indicate that every individual variable construct has higher values than the other constructs.

Table 5. Discriminant Validity

\begin{tabular}{|c|c|c|c|c|c|c|c|c|c|}
\hline & CR & AVE & $\begin{array}{c}\text { Work } \\
\text { life } \\
\text { balance }\end{array}$ & Salary & Satisfaction & Benefits & $\begin{array}{c}\text { Structural } \\
\text { capital }\end{array}$ & $\begin{array}{c}\text { Job } \\
\text { nature }\end{array}$ & Opportunities \\
\hline $\begin{array}{l}\text { Work life } \\
\text { balance }\end{array}$ & 0.859 & 0.67 & 0.832 & & & & & & \\
\hline Salary & 0.812 & 0.625 & 0.057 & 0.789 & & & & & \\
\hline Satisfaction & 0.788 & 0.539 & $0.172 *$ & $0.254 * *$ & 0.73 & & & & \\
\hline Benefits & 0.884 & 0.796 & 0.049 & $0.336 * * *$ & 0.143 & 0.891 & & & \\
\hline $\begin{array}{c}\text { Structural } \\
\text { capital }\end{array}$ & 0.619 & 0.453 & 0.156 & $-0.196 *$ & -0.163 & 0.043 & 0.582 & & \\
\hline Job nature & 0.579 & 0.687 & 0.014 & 0.015 & 0.054 & 0.156 & 0.056 & 0.616 & \\
\hline Opportunity & 0.789 & 0.578 & 0.078 & 0.065 & 0.145 & 0.045 & 0.074 & 0.075 & 0.754 \\
\hline
\end{tabular}

Path analysis has been presented in table 6 to summarize the impact of compensation management strategies on talent retention with the mediation of structural capital. The results have shown a significant and positive impact of work life balance $(\mathrm{P}=0.033)$, satisfaction $(\mathrm{P}=0.016)$, and benefits $(\mathrm{P}=0.001)$ on opportunity; therefore, accepting $\mathrm{H} 1 \mathrm{a}, \mathrm{H} 3 \mathrm{a}$, and $\mathrm{H} 4 \mathrm{a}$. However, the results fail to find a significant impact of salary on the opportunity $(\mathrm{P}=0.671)$; thus, rejecting $\mathrm{H} 2 \mathrm{a}$. In addition, the results have found an insignificant mediation of structural capital on opportunity $(\mathrm{P}=0.128)$; therefore, rejecting H5a. Whereas, the results revealed a significant mediation impact on job nature $(\mathrm{P}=0.002)$; therefore, accepting H6a. Similarly, the results have found a significant impact of work life balance, salary, satisfaction, and benefits on the job nature of employees; thus, accepting H7a, H8a, H9a, and H10a.

Table 6. Path Analysis

\begin{tabular}{|c|c|c|c|c|c|c|}
\hline & & & Estimate & S.E. & T-Stats & P Value \\
\hline Work life balance & $\begin{array}{l}<-- \\
\end{array}$ & Opportunity & 0.097 & 0.061 & 2.431 & 0.033 \\
\hline Salary & $<---$ & Opportunity & 0.050 & 0.098 & 0.464 & 0.671 \\
\hline Satisfaction & $<---$ & Opportunity & 0.127 & 0.074 & 2.836 & 0.016 \\
\hline Benefits & $<---$ & Opportunity & 0.461 & 0.088 & 4.535 & 0.001 \\
\hline Structural capital & $<---$ & Opportunity & -0.145 & 0.077 & -1.561 & 0.128 \\
\hline Structural capital & $<---$ & Job nature & 0.024 & 0.075 & 2.140 & 0.002 \\
\hline Work life balance & $<---$ & Job nature & 0.011 & 0.068 & 1.215 & 0.007 \\
\hline Salary & $<---$ & Job nature & 0.456 & 0.086 & 2.140 & 0.003 \\
\hline Satisfaction & $<---$ & Job nature & 0.564 & 0.094 & 1.158 & 0.035 \\
\hline Benefits & $<---$ & Job nature & 0.452 & 0.065 & 2.179 & 0.013 \\
\hline
\end{tabular}

\section{Discussion}

The results of the study reveal that the compensation management strategy involving structural capital is beneficial for the retention of the commercial banking sector employees in Jordan. These results are supported by the study of Chiekezie et al. (2017) which also employed the same structural capital strategy for the commercial banks in Nigeria. The inclusion of work-life balance as a part of the compensation management improves employee satisfaction and retention as per the study findings. These are corroborated by the study of Deery, M., and Jago, L. (2015) which assessed talent management as well as work-life balance.

Various other studies such as Zahoor et al. (2015) and Kakar et al. (2015) have highlighted the significant impact of work-life balance and employee tenure in a firm. Based on the present study findings, the study has found that the salary has a positive impact on the retention though its negative impact on development opportunities is 
reported. Abu Jadayil (2011) has endorsed the study findings by reporting a positive impact of salary on the retention of industrial sector employees in Jordan. Moreover, the present study has also reported an insignificant relationship between salary and job nature consistent with the study findings of Malik et al. (2012).

Firm structure impact has been stated positive, which is in-line with the previous study of Aramburu and Sáenz (2011). Hosnavi and Ramezan (2011) on intellectual and firm capital also found similar results indicating improved retention rate of the employees. Further, the use of structural capital has also improved the retention as its integration induces an interaction among the employees. This improved the knowledge of the employee helping in his career progression and increasing retention prospects. The study of Brookes et al. (2007) is found parallel to the present study highlighting that social structure improves the retention of the employees as well as their performance. Also, the study has reported a negative impact of structural capital on the opportunity to grow. These results are found conflicting to the study outcomes of Wang (2011) on Taiwan capital market. Furthermore, the findings also reveal that salary and job nature have a negative relationship in the retention of the employee as endorsed by the study of Malik et al. (2012).

The results of the present study suggest that if employees are provided with training and development opportunities, their association length and level with the firm enhances. This statement is mentioned by the study of Karve and Dias (2016) which indicated the positive outcome of training and development on talent retention. Overall outcomes of the present study suggest that the compensation management of the employees produces a positive outcome on employee retention. These are parallel to Rahim et al. (2011) which stated that developing effective compensation policies allows the firms to attract, satisfy, retain as well as motivate employees, driving their satisfaction and retention level upward. This also helps in the formation of a competitive advantage in assisting the firms in the achievement of its business objectives.

The study also reports certain shortcomings in terms of its generalizability due to its limitation of the business sector and region. Given this, more studies on different regions can be conducted for evaluating the impact of compensation management on the employee retention inducing in the component of structural capital. Also, qualitative design can be adopted for improving the existing knowledge of compensation management and structural capital.

\section{Conclusion}

The study concludes that the compensation strategies allow the firm to not only retain its employees but also improve the employee satisfaction leading to their retention in the firm. Along with it, the support of the employees through educating and training them may act as a stimulation tool for their retention in the firm. Based on the findings, the study urges the commercial banks in Jordan to endeavor towards realizing effective practices for retaining their best talent. It further suggests attaining equilibrium among the firm objectives and employee individual goals which allows it to combat the employee retention challenges.

During conducting the study, some limitations have been noticed concerning its generalizability. Such as applying, the study findings stand limited to Jordan and to commercial banks. Moreover, the study guides future investigation of the moderating influence of spiritual capital within firms. In addition, the administrators' role can be assessed regarding talent retention.

\section{Acknowledgement}

The author is thankful to everyone who helped directly or indirectly in the preparation of this study. It is worth mentioning that the author has no conflict of interest in any way or shape during the process of conducting the study, it also should be known that this study is not funded by any entity.

\section{References}

Abu Jadayil, W. M. (2011). Main Factors Causing Workers Turnover in Jordan Industrial Sector. Jordan Journal of Mechanical \& Industrial Engineering, 5(2), 161-166.

Adeoye, A. O., \& Fields, Z. (2014). Compensation management and employee job satisfaction: A case of Nigeria. Journal of Social Sciences, 41(3), 345-352. https://doi.org/10.1080/09718923.2014.11893369

Ahmed, I., Ramzan, M., Mohammad, S. K., \& Islam, T. (2011). Relationship between Perceived Fairness in Performance Appraisal and OCB; Mediating Role of Organizational Commitment. International Journal of Academic Research, 3(5), 15-20.

Aramburu, N., \& Sáenz, J. (2011). Structural capital, innovation capability, and size effect: An empirical study. Journal of Management \& Organization, 17(3), 307-325. https://doi.org/10.1017/S1833367200001498

Ashar, M., Ghafoor, M., Munir, E., \& Hafeez, S. (2013). The impact of perceptions of training on employee 
commitment and turnover intention: Evidence from Pakistan. International Journal of Human Resource Studies, 3(1), 74-88. https://doi.org/10.5296/ijhrs.v3i1.2924

Bartlett, C., \& Ghoshal, S. (2013). Building competitive advantage through people. Sloan Management Review, $43(2)$.

Brookes, N. J., Morton, S. C., Grossman, S., Joesbury, P., \& Varnes, D. (2007). Analyzing social capital to improve product development team performance: Action-research investigations in the aerospace industry with TRW and GKN. IEEE Transactions on Engineering Management, 54(4), 814-830. https://doi.org/10.1109/TEM.2007.906859

Chiekezie, O. M., Emejulu, G., \& Nwanneka, A. (2017). Compensation Management and Employee Retention of Selected Commercial Banks in Anambra State, Nigeria. Archives of Business Research, 5(3), 114-127. https://doi.org/10.14738/abr.53.2758

Cole, D. A. (1987). Utility of confirmatory factor analysis in test validation research. Journal of Consulting and Clinical Psychology, 55(4), 584-594. https://doi.org/10.1037/0022-006X.55.4.584

Deery, M., \& Jago, L. (2015). Revisiting talent management, work-life balance, and retention strategies. International Journal of Contemporary Hospitality Management, 27(3), 453-472. https://doi.org/10.1108/IJCHM-12-2013-0538

Gogan, L. M., Duran, D. C., \& Draghici, A. (2015). Structural capital-A proposed measurement model. Procedia Economics and Finance, 23, 1139-1146. https://doi.org/10.1016/S2212-5671(15)00503-1

Gratton, L., \& Erickson, T. J. (2007). Eight ways to build collaborative teams. Harvard Business Review, 85(11), 101-109.

Guan, Y., Zhou, W., Ye, L., Jiang, P., \& Zhou, Y. (2015). Perceived organizational career management and career adaptability as predictors of success and turnover intention among Chinese employees. Journal of Vocational Behavior, 88, 230-237. https://doi.org/10.1016/j.jvb.2015.04.002

Haider, M., Rasli, A., Akhtar, C. S., Yusoff, R. B. M., Malik, O. M., Aamir, A., ... \& Tariq, F. (2015). The impact of human resource practices on employee retention in the telecom sector. International Journal of Economics and Financial Issues, 5(1S), 63-69.

Hair, J. F., Black, W. C., Babin, B. J., Andersom, R. E., \& Tatham, R. L. (2010). Multivariate Data Analysis. Pearson Prentice Hall: New Jersey.

Hosnavi, R., \& Ramezan, M. (2011). Intellectual capital and organizational organic structure: how are these concepts related? Trends in Applied Sciences Research, 6(3), 256-268. https://doi.org/10.3923/tasr.2011.256.268

Ismail, M. (2005). The influence of intellectual capital on the performance of Telekom Malaysia (Doctoral dissertation, Universiti Teknologi Malaysia).

Kakar, P., Raziq, A., \& Khan, F. (2017). Impact of Human Resource Management Practices on Employee Retention: A Case of Banking Sector in Quetta Baluchistan. Journal of Management Info, 4(3), 5-11. https://doi.org/10.31580/jmi.v5i1.24

Karve, S., \& Dias, S. (2016). HRM practices and retention of employees in hotel industry in South Mumbai. International Journal of Multidisciplinary Approach and Studies, 3(3), 13-19.

Lim, E. Z., Phang, Z. B., Foong, M. L., S'ng, J. H. M., \& Tiong, X. Y. (2015). Talent retention: A study in Malaysia manufacturing industry (Doctoral dissertation, UTAR).

Loan-Clarke, J., Arnold, J., Coombs, C., Hartley, R., \& Bosley, S. (2010). Retention, turnover, and return-a longitudinal study of allied health professionals in Britain. Human Resource Management Journal, 20(4), 391-406. https://doi.org/10.1111/j.1748-8583.2010.00140.x

Lowers \& Associates (2018).The State of Employee Turnover and Retention in the Workplace. The Risk Management Blog. Accessible at: http://blog.lowersrisk.com/employee-turnover-and-retention/

Mabaso, C. M., \& Dlamini, B. I. (2017). Impact of Compensation and Benefits on Job Satisfaction. Research Journal of Business Management, 11(2), 80-90. https://doi.org/10.3923/rjbm.2017.80.90

Malik, M. E., Danish, R. Q., \& Munir, Y. (2012). The impact of pay and promotion on job satisfaction: Evidence from higher education institutes of Pakistan. American Journal of Economics, 10(5), 6-9. https://doi.org/10.5923/j.economics.20120001.02 
Mertins, K., Will, M., \& Meyer, C. (2009, April). InCaS: Intellectual Capital Statement. Measuring intellectual capital in European small-and medium sized enterprises. In Proceedings of the European Conference on Intellectual Capital (pp. 353-362).

Michael, B., Prince, A. F., \&Chacko, A. (2016). Impact of Compensation Package on Employee Retention. CLEAR International Journal of Research in Commerce \& Management, 7(10), 36-41.

Mokaya, S. O., \& Kipyegon, M. J. (2014). Determinants of employee engagement in the Banking industry in Kenya; case of cooperative bank. Journal of Human Resources Management and Labor Studies, 2(2), 187-200.

Obeidat, B. Y., Abdallah, A. B., Aqqad, N. O., Akhoershiedah, A. H. O. M., \& Maqableh, M. (2016). The effect of intellectual capital on organizational performance: the mediating role of knowledge sharing. Communications and Network, 9(01), 1-27. https://doi.org/10.4236/cn.2017.91001

Polit, F. D., \& Beck, C. T. (2016). Nursing Research: Generating and Assessing evidence for evidence-based Practice.

Rahim, N., R, Mat, C., R., \& Mohd Kamal, M., H. (2011). Structural capital and its effect on organizational performance: A case study of Telekom Malaysia Berhad (TM) headquarters Article.

Samuel, M. O., \& Chipunza, C. (2009). Employee retention and turnover: Using motivational variables as a panacea. African journal of business management, 3(9), 410-415.

Shahnawaz, M. G., \& Jafri, M. H. (2009). Psychological capital as predictors of organizational commitment and organizational citizenship behavior. Journal of the Indian Academy of Applied Psychology, 35(Special Issue), 78-84.

Walia, B., \& Bajaj, K. (2012). Impact of human resource management (HRM) practices on employee retention. International Journal of Research in IT \& Management, 2(2), 836-847

Wang, M. (2011). Measuring intellectual capital and its effect on financial performance: evidence from the capital market in Taiwan. Frontiers of Business Research in China, 5(2), 243-265. https://doi.org/10.1007/s11782-011-0130-7

Weigold, I. K., Porfeli, E. J., \& Weigold, A. (2013). Examining tenets of personal growth initiative using the Personal Growth Initiative Scale-II. Psychological Assessment, 25(4), 1396-1403. https://doi.org/10.1037/a0034104

Yin-Fah, B. C., Foon, Y. S., Chee-Leong, L., \& Osman, S. (2010). An exploratory study on turnover intention among private sector employees. International Journal of Business and Management, 5(8), 57-64.

Zahoor, A., Ijaz, S., \&Muzammil, T. (2015). Impact of human resource management practices on employee retention in telecom sector of Pakistan. Journal of Resources Development and Management, 12(1), 22- 31.

\section{Copyrights}

Copyright for this article is retained by the author(s), with first publication rights granted to the journal.

This is an open-access article distributed under the terms and conditions of the Creative Commons Attribution license (http://creativecommons.org/licenses/by/4.0/). 